\title{
Magnetic properties of subaerial basalts at low temperatures
}

\author{
Andrei Kosterov* \\ Marine Geology Department, Geological Survey of Japan, 1-1-3 Higashi, Tsukuba 305-8567, Japan
}

(Received July 12, 2000; Revised June 15, 2001; Accepted June 18, 2001)

\begin{abstract}
Magnetic properties have been measured as a function of temperature from $2 \mathrm{~K}$ to room temperature for twentyone samples of subaerial basalts of different origin and age, using an MPMS instrument. In all samples but four, titanomagnetite with a titanium content of less than 5 per cent has been determined as a dominant magnetic mineral carrying NRM from $\chi(T)$ measurements above room temperature and Verwey transition observations. However, the new low-temperature experiments yielded evidence of the presence of another magnetic mineral in all samples. This mineral accounts for up to 70 per cent of saturation magnetization at $2 \mathrm{~K}$ and acquires a relatively strong but thermally unstable SIRM at this temperature. Comparison of susceptibility vs. temperature curves measured in low and high DC biasing fields reveals evidence of superparamagnetic behavior, peaks marking the effective blocking temperatures being shifted from $<2 \mathrm{~K}$ to about $16 \mathrm{~K}$ by a $4.8 \mathrm{~T}$ DC magnetic field. At the same time, the presence of peaks in the high-field susceptibility curves indicate that the corresponding magnetic phase does not reach saturation, even in the highest field available to us. A possible candidate to account for these properties is a hemoilmenite with 8-10 mole per cent of hematite, originating from high-temperature deuteric oxidation. This is in accordance with the prevailing occurrence of exsolution lamellae within titanomagnetite grains observed in scanning electron microscopy (SEM) images.
\end{abstract}

\section{Introduction}

Volcanic rocks are commonly regarded as the most reliable recorders of the paleomagnetic field. Of them, the most suitable for paleomagnetism are the rocks in which the initial Ti-rich titanomagnetite has undergone high-temperature deuteric oxidation, forming submicron-sized magnetite-rich grains embedded in a predominantly ilmenite-rich matrix (Buddington and Lindsley, 1964; Haggerty, 1976). Small single-domain (SD) or pseudo-single-domain (PSD) magnetite grains are then capable of preserving their magnetization over tens and hundreds of millions of years (Banerjee, 1991; Dunlop and Özdemir, 1997). The formation of magnetite through the process of deuteric oxidation also ensures that the primary natural remanent magnetization (NRM) of a rock is a thermoremanent magnetization (TRM). The latter condition is the pre-requisite for attempting to determine absolute paleointensity by the Thellier or similar methods (Thellier and Thellier, 1959).

Among other techniques, low-temperature measurements have been widely used to investigate the magnetic mineralogy of volcanic rocks. However, in most cases measurements have been carried out only above $77 \mathrm{~K}$ (Nagata et al., 1964; Merrill, 1970; Radhakrishnamurty et al., 1981; Senanayake and McElhinny, 1981, 1982; Hodych, 1982, 1990, 1991; Sherwood, 1988; Thomas, 1993), effectively limiting the studies to characterizing only the magnetite

*Present address: Earth and Planetary Science Department, Tokyo Institute of Technology, 2-12-1 Ookayama, Meguro, Tokyo 152-8551, Japan.

Copy right (c) The Society of Geomagnetism and Earth, Planetary and Space Sciences (SGEPSS); The Seismological Society of Japan; The Volcanological Society of Japan; The Geodetic Society of Japan; The Japanese Society for Planetary Sciences. and/or titanomagnetites present. Very little has been reported so far on the magnetic properties of volcanic and, in particular, of the basaltic rocks below $77 \mathrm{~K}$ (Moskowitz et al., 1998; Shau et al., 2000). Nevertheless, even these limited data show a potential of low-temperature magnetometry in characterizing the magnetic mineralogy of basalts. The present work has been therefore aimed at further investigating the magnetic properties of basalts in the $2-300 \mathrm{~K}$ temperature range, with emphasis on the behavior at very low temperatures.

\section{Samples}

Twenty-one samples of basaltic rocks of different origin and age have been selected for the present study. These include hotspot volcanics from Réunion Island and Tahiti, and plateau basalts from Greenland, Paraná and Karoo igneous provinces (Table 1). Sister specimens of these samples were previously used, with variable success, for Thellier paleointensity studies (Chauvin et al., 1990, 1991; Kosterov et al., 1997, 1998; Kosterov and Prévot, 1998; Riisager and Abrahamsen, 2000). Hysteresis loop parameters at room temperature measured previously (Table 1) suggest the dominantly PSD state for all samples, as commonly observed in many basaltic rocks.

Magnetic mineralogy of the samples was first investigated using conventional high-temperature techniques. Curie points were determined from the study of temperature-dependences of low-field susceptibility. Susceptibility vs. temperature curves were measured in vacuum using a Bartington MS 2 instrument connected with a furnace (Université Montpellier II). Most of the susceptibility vs. temperature curves are more or less reversible (Fig. 1(a)) but some show 
Table 1. Magnetic properties of the samples used in the present study. $T_{c}(\mathrm{HT})$ is the Curie temperature of the titanomagnetite phase determined from $\chi(T)$ heating curves; $T_{c}$ (LT) is the Curie temperature of the hemoilmenite phase determined as described in text; Verwey transition temperatures $\left(T_{v}\right)$ were determined from SIRM(T) zero-field warming curves (first values) and from $\chi^{\prime}(T)$ curves (second values). Hysteresis was measured in $0.8 \mathrm{~T}$ (Lesotho and Paraná samples) or $1.5 \mathrm{~T}$ maximum field.

\begin{tabular}{|c|c|c|c|c|c|c|c|c|}
\hline \multirow[b]{2}{*}{ Sample } & \multirow[b]{2}{*}{ Reference } & \multirow[b]{2}{*}{$T_{c}(\mathrm{HT})\left({ }^{\circ} \mathrm{C}\right)$} & \multirow[b]{2}{*}{$T_{c}(\mathrm{LT})(\mathrm{K})$} & \multirow[b]{2}{*}{$T_{v}(\mathrm{~K})$} & \multicolumn{4}{|c|}{ Hysteresis parameters } \\
\hline & & & & & $H_{c}(\mathrm{mT})$ & $H_{c r}(\mathrm{mT})$ & $J_{r s} / J_{s}$ & $H_{c r} / H_{c}$ \\
\hline Tahiti & Chauvin et al. (1990) & & & & & & & \\
\hline BKB52 & & 525 & 21 & $101 / 94$ & 36.3 & 62.1 & 0.321 & 1.71 \\
\hline BKР143 & & 540 & 23 & $95 / 97$ & 32.0 & 63.6 & 0.273 & 1.99 \\
\hline PG50 & & 540 & 22 & $108 / 102$ & 28.4 & 44.6 & 0.301 & 1.57 \\
\hline R1D24 & & $\sim 150 ; 435 ?$ & 22 & no & 17.4 & 33.3 & 0.267 & 1.91 \\
\hline & & 505 & & & & & & \\
\hline Réunion & Chauvin et al. (1991) & & & & & & & \\
\hline RB127 & & 470 & 22 & $\mathrm{No} /(92)$ & 16.3 & 34.4 & 0.211 & 2.11 \\
\hline RB145 & & 490 & 22 & $111 /(94)$ & 17.8 & 34.4 & 0.245 & 1.93 \\
\hline Greenland & Riisager and Abrahamsen (2000) & & & & & & & \\
\hline 410732 & & $545 ; 575$ & 33 & $105 / 101$ & 19.3 & 42.9 & 0.147 & 2.22 \\
\hline 410734 & & $540 ; 555$ & 24 & $101 / 99$ & 16.9 & 39.5 & 0.138 & 2.33 \\
\hline 410866 & & $\begin{array}{c}570 \text { - Produced } \\
\text { on heating? }\end{array}$ & 21 & no & 5.1 & 22.8 & 0.096 & 4.42 \\
\hline 410892 & & $480 ; 555$ & 24 & $102 / 99$ & 16.9 & 33.8 & 0.155 & 2.00 \\
\hline 410896 & & $545 ; 565$ & 23 & $109 / 105$ & 23.8 & 46.0 & 0.204 & 1.93 \\
\hline Paraná & Kosterov et al. (1998) & & & & & & & \\
\hline $91 \mathrm{M} 133$ & & 545 & 26 & $98 / 94$ & 27.0 & 64.5 & 0.262 & 2.39 \\
\hline $91 \mathrm{M} 148$ & & 535 & 21 & $104 / 105$ & 22.7 & 41.5 & 0.221 & 1.83 \\
\hline Lesotho & Kosterov et al. (1997); & & & & & & & \\
\hline (Karoo) & Kosterov and Prévot (1998) & & & & & & & \\
\hline $92 \mathrm{M} 333$ & & 565 & 29 & $114 / 113$ & 20.5 & 48.2 & 0.159 & 2.35 \\
\hline 92P182 & & 565 & 23 & $111 / 110$ & 21.9 & 42.8 & 0.183 & 1.95 \\
\hline $92 \mathrm{M} 021$ & & $425 ; 535 ; 550$ & 24 & $95 / 93$ & 15.7 & 31.0 & 0.212 & 1.97 \\
\hline $92 \mathrm{M} 047$ & & 580 & 24 & $108 / 103$ & 17.7 & 37.4 & 0.180 & 2.11 \\
\hline $92 \mathrm{M} 086$ & & $380 ; 545$ & 26 & $99 / 97$ & 10.5 & 24.8 & 0.179 & 2.36 \\
\hline 92M117 & & 555 & 25 & $101 / 98$ & 16.8 & 37.1 & 0.188 & 2.21 \\
\hline 92M199 & & $540 ; 555$ & 40 & $114 / 111$ & 29.1 & 51.4 & 0.282 & 1.77 \\
\hline $92 \mathrm{M} 244$ & & 535 & 29 & $108 / 104$ & 16.9 & 37.3 & 0.153 & 2.21 \\
\hline
\end{tabular}
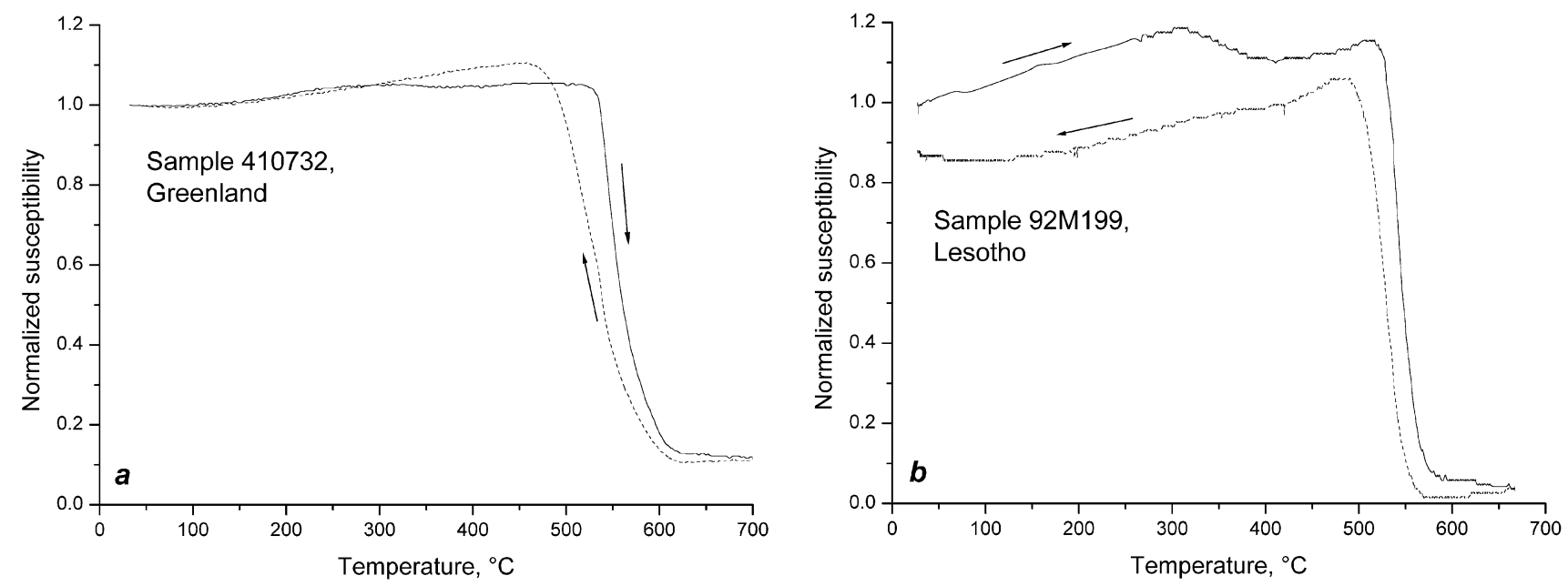

Fig. 1. Examples of susceptibility vs. temperature curves. Solid lines-heating curves; dashed lines-cooling curves. 

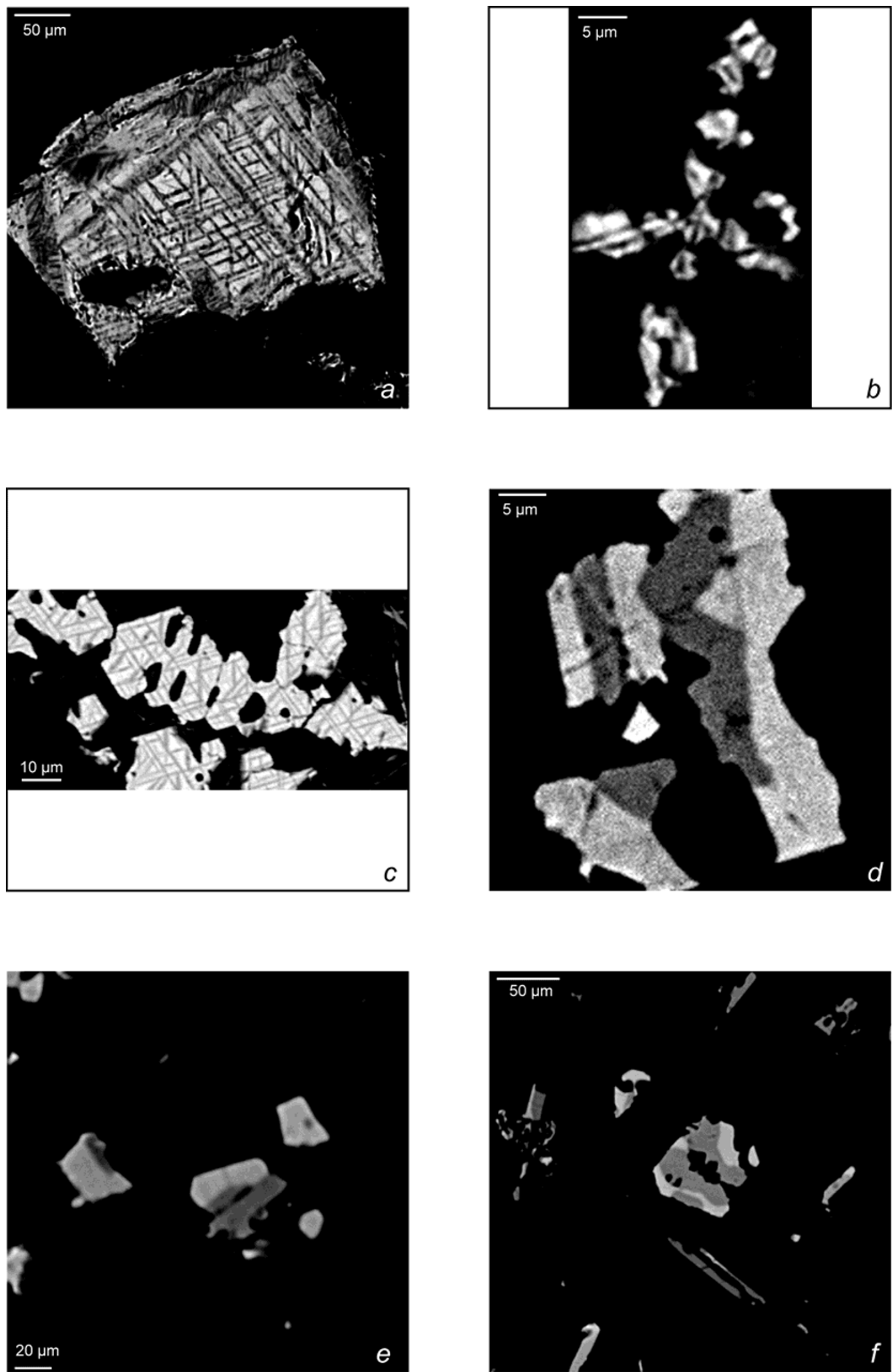

Fig. 2. SEM images of the titanomagnetite grains present in the basalts under study. (a) Lesotho, sample 92M244. A large anhedral grain showing a trellis-type exsolution in the central part and a more advanced oxidation in the outer parts; (b) Lesotho, sample 92M021. A skeletal grain with a trellis-type exsolution; (c) Greenland, sample 410732. A skeletal grain with a trellis-type exsolution; (d) Paraná, sample 91M148. Titanomagnetite grains of irregular shape showing a sandwich-type exsolution; (e) Tahiti, sample R1D24. Relatively small titanomagnetite grains showing either no or a sandwich-type exsolution; (f) Réunion, sample RB127. A large anhedral titanomagnetite grain with a sandwich-type exsolution, and relatively small irregular shaped grains showing either no or a sandwich-type exsolution. 
peaks at moderate temperatures that do not appear in the cooling curves (Fig. 1(b)). In this particular case, this feature was interpreted as resulting from an irreversible change in the domain structure of ferrimagnetic grains, rather than from chemical alteration, for the reason that no irreversible changes in saturation magnetization occurred within this temperature range (Kosterov and Prévot, 1998). Curie temperatures were determined from heating curves only; however only the features replicated in the cooling curves were taken for the determination. A natural sample might be expected to show a range of Curie temperatures rather than a single Curie point. Therefore, an effective Curie temperature has been determined as the temperature at which the rate of decrease in susceptibility was maximal. In some cases, however, two closely spaced maxima yielded better fit to the data and therefore two Curie temperatures close to each other are quoted for these samples. Thirteen samples out of the twenty-one yielded a single Curie point ranging from 470 to $580^{\circ} \mathrm{C}$. It is worth noting, however, that the quoted Curie temperatures are the mean values in the sense described above, and some samples show a considerable spread of actual Curie temperatures around the mean (see, e.g., Fig. 1(a)). Seven samples have two, or possibly three, Curie points, the highest one always above $500^{\circ} \mathrm{C}$. Sample 410866 of Greenland basalt is somewhat peculiar, since, having the Curie point of $570^{\circ} \mathrm{C}$, i.e. very close to that of pure magnetite, it shows no trace of the Verwey transition at low temperature. It is therefore likely that this magnetite phase is not primary but produced by heating.

Representative samples have been investigated with scanning electron microscopy (SEM) using an EPMA JEOL instrument at the Geological Survey of Japan, Tsukuba. The dominant opaque phase appears to be titanomagnetite (TM); primary ilmenite was observed only occasionally. The size and shape of the original titanomagnetite grains varied considerably between samples (Fig. 2). Some samples, e.g. 92M244 and 92M333, showed large anhedral or euhedral grains up to $100-200 \mu \mathrm{m}$ in size; others, such as 92M086 and 92M021, showed mostly skeletal, dendritic, or irregular shaped grains generally $<20 \mu \mathrm{m}$ in size. In the case of the Lesotho samples, the characteristic shape of titanomagnetite grains is clearly determined by the position of the sample in a lava flow, larger and more regularly shaped grains occurring in the samples drilled from the central parts of the respective lavas (Kosterov and Prévot, 1998). In the sample 410732 from Greenland grains are mostly skeletal shaped, but their size can reach several tens of microns (Fig. 2(c)). In the Lesotho and Greenland samples, TM grains show mostly trellis-type exsolutions (Buddington and Lindsley, 1964), suggesting the oxidation stage C3 or in some cases possibly C4, according to the classification of Haggerty (1976). Sample 91M148 from Paraná shows rather irregularly shaped grains $20-30 \mu \mathrm{m}$ in size with sandwich-type exsolutions (Fig. 2(d)). In the samples from Tahiti and Réunion, mostly anhedral grains several tens of microns in size and smaller irregular shaped grains are observed; exsolutions, if any, are dominantly of the sandwich type (Figs. 2(e), (f)).

\section{Low-Temperature Magnetic Measurements}

First, thermal decay of saturation isothermal remanent magnetization (SIRM) acquired at $15 \mathrm{~K}$ in a $2.5 \mathrm{~T}$ magnetic field was measured to detect the presence or absence of the Verwey transition. These measurements were made with a Magnetic Properties Measurement System (MPMS) at the Institute for Rock Magnetism, Minneapolis, U.S.A. Further low-temperature measurements were carried out with an MPMS XL instrument at the Geological Survey of Japan, Tsukuba. Temperature curves of the AC complex susceptibility $\chi=\chi^{\prime}-i \chi^{\prime \prime}$ from $2 \mathrm{~K}$ to room temperature were measured twice, first at zero and then in a $4.8 \mathrm{~T}$ magnetic field. In the latter experiment, the high-field magnetization has been monitored alongside the susceptibility. The AC driving field of $10 \mathrm{~Hz}$ frequency and $100 \mu \mathrm{T}$ amplitude was used. For a few selected samples, thermal decay of SIRM acquired at $2 \mathrm{~K}$ in a $5 \mathrm{~T}$ field was remeasured in the same temperature range and hysteresis loops traced at several different temperatures between 5 and $90 \mathrm{~K}$.

\section{The Verwey Transition}

The Verwey transition temperatures, determined from peaks in the derivatives of $\operatorname{SIRM}(\mathrm{T})$ and $\chi^{\prime}(T)$ curves, are listed in Table 1. Seventeen out of the twenty-one samples have the well-defined Verwey transition (Fig. 3), transition temperatures generally tending to decrease with decreasing Curie temperatures. Here, it is worth noting that the transition temperatures determined from the susceptibility curves are in most cases lower by a few degrees than those determined from the SIRM(T) curves. Stoichiometric titanomagnetites richer in titanium than TM04 do not show the Verwey transition (Kozłowski et al., 1996b), while the Curie point of titanomagnetites of this composition is about $545^{\circ} \mathrm{C}$ (e.g. O'Reilly, 1984). On the other hand, some of the samples used in the present study display the Verwey transition while having Curie points below $540^{\circ} \mathrm{C}$. Two possibilities can be invoked to explain this. First, it is quite likely that titanomagnetites in these samples occur in a continuous range of compositions starting from nearly pure magnetite. Second, other minor impurities, most notably $\mathrm{Mg}$ and $\mathrm{Al}$, tend to lower the Curie point, while their effect on the Verwey temperature is much smaller than that of Ti (Kozłowski et al., 1996a; Brabers et al., 1998). Most probably, both mechanisms play a role in the behavior of the samples used in the present study. A Curie point measurement would then average the contributions from the whole range of compositions present, while the Verwey temperature would only reflect an average composition of the material close to pure magnetite.

Only four samples do not display the Verwey transition. For sample R1D24, the highest Curie temperature is $505^{\circ} \mathrm{C}$, suggesting a magnetic mineral with a composition of about TM10 that does not show the transition (Kozłowski et al., 1996b). Sample 410866 has a paramagnet-like $\chi(T)$ curve with only minor magnetite phase having the Curie point of $570^{\circ} \mathrm{C}$. Considering the absence of the Verwey transition in either $\operatorname{SIRM}(\mathrm{T})$ or $\chi^{\prime}(T)$ curves, it seems likely that this magnetite was produced during heating. Two samples from the Réunion Island, RB127 and RB145, show different behavior (Fig. 4). They do not display a signature of the Verwey transition in the SIRM(T) curves except perhaps for 

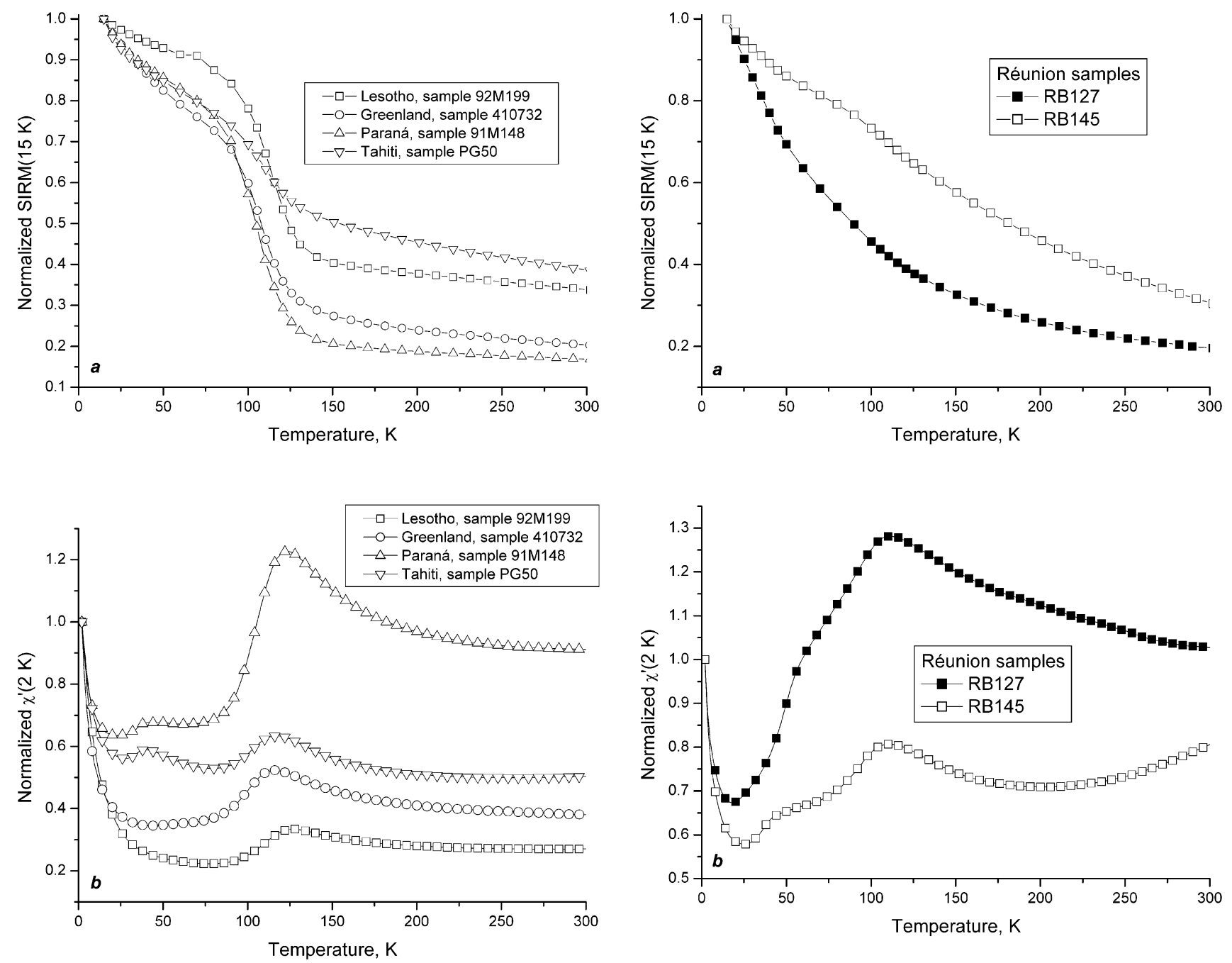

Fig. 3. (a) $\operatorname{SIRM}(T)$ and (b) $\chi^{\prime}(T)$ curves for the samples showing the Verwey transition.

a small feature in the RB145, which might be interpreted as a transition with $T_{v}$ about $110 \mathrm{~K}$. On the other hand, these two samples show maxima in the susceptibility vs. temperature curves just near that temperature. Differentiation of these curves yields apparent transition temperatures of 92 and $94 \mathrm{~K}$ respectively (values in parentheses in Table 1). However, absence of the corresponding strong loss of SIRM in the same temperature interval excludes the interpretation of these maxima as evidence for the Verwey transition. Titanomagnetite in the two samples from Réunion probably has a composition of about TM10-15. TM10 is known to show the isotropic point slightly below $100 \mathrm{~K}$ (Syono, 1965). Based on this result, Clark and Schmidt (1982) have theoretically predicted that multidomain TM10 should exhibit a peak in susceptibility around this temperature. Moskowitz et al. (1998) has reported $\operatorname{SIRM(T)}$ and $\chi^{\prime}(T)$ curves for a suite of synthetic single crystal titanomagnetites in the composition range from TM0 to TM60. The sample with the nominal composition of TM05 showed a maximum in the $\chi^{\prime}(T)$ curve at $85 \mathrm{~K}$, while its SIRM decreased rather gradually between 20 and $80 \mathrm{~K}$. Sample TM19, on the other hand, showed a rapid loss of SIRM be-

Fig. 4. (a) $\operatorname{SIRM}(T)$ and (b) $\chi^{\prime}(T)$ curves for the samples from Réunion. While showing a susceptibility peak at about $110 \mathrm{~K}$, those samples do not exhibit a transition in SIRM vs. temperature curves.

tween 30 and $50 \mathrm{~K}$; its susceptibility increased rapidly below ca. $100 \mathrm{~K}$ and at a much slower rate above this temperature. The $\chi^{\prime}(T)$ curves measured for RB127 and RB145 might be therefore viewed as intermediate between the TM05 and TM19 curves of Moskowitz et al. (1998), while the much smaller decrease of SIRM with temperature is may be due to a rather small size of titanomagnetite grains in these samples.

In stoichiometric magnetite out-of-phase (quadrature) susceptibility $\chi^{\prime \prime}$ also shows a singularity at the Verwey transition (Šimša et al., 1985; Skumryev et al., 1999). In these two studies, mm-size single crystals were used. To the best of the author's knowledge, temperature variation of $\chi^{\prime \prime}$ has not been reported previously neither for synthetic finegrained magnetite nor for natural magnetite-bearing samples. Examples of the temperature curves of the phase angle $\phi$ which is related to $\chi^{\prime \prime}$ through the equation $\phi=$ $\tan ^{-1}\left(\chi^{\prime \prime} / \chi^{\prime}\right)$, are given in Fig. 5. Surprisingly, the behavior of all the samples studied near the Verwey transition is very similar. Independent of the 'bulk' transition temperature, all samples, without exception, show the same two jumps in the phase angle: a larger one, on the order of $0.1^{\circ}$, at $122 \mathrm{~K}$, 


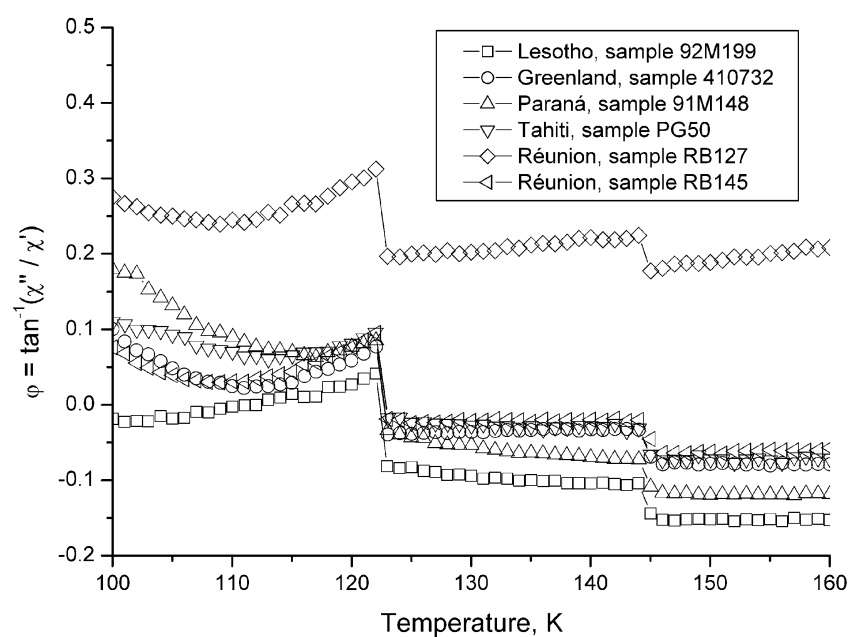

Fig. 5. Examples of temperature dependences of the phase angle $\phi=\tan ^{-1} \chi^{\prime \prime} / \chi^{\prime}$, showing jumps at 122 and $144 \mathrm{~K}$. Symbol size approximately corresponds to a measurement error.

and a smaller jump at $144 \mathrm{~K}$. The first jump is the manifestation of the Verwey transition. The origin of the second jump is not quite clear, but tentatively it may be associated with the switching of the easy magnetization axis of magnetite from [110] to [111] crystallographic direction. Observation of the jump of $\chi^{\prime \prime}$ at $122 \mathrm{~K}$, i.e. exactly at the Verwey temperature of the stoichiometric magnetite (Aragón et al., 1985; Aragón, 1992) is in apparent contradiction with the Verwey transition temperatures determined from $\operatorname{SIRM}(\mathrm{T})$ and $\chi^{\prime}(T)$ curves and with the Curie temperatures. Moreover, the $122-\mathrm{K}$ jump is observed even in the samples that do not show the 'bulk' Verwey transition (R1D24, RB127, RB145, and 410866). This suggests that a small amount of essentially stoichiometric magnetite is present in all studied samples, even though it cannot be detected by other magnetic measurements.

\section{Magnetic Properties at Very Low Temperatures}

At very low temperatures (thereafter this term is used to designate, somewhat loosely, the temperature interval below $30 \mathrm{~K}$ ) low-field susceptibility of studied samples is characterized by a rapid decrease (Figs. 3(b) and 4(b)). The loss of susceptibility is typically about 40 per cent of the $2-\mathrm{K}$ value, but can be as large as 75 per cent (e.g. sample 92M199). On the other hand, the high-field susceptibility curves, measured in a $4.8 \mathrm{~T}$ steady field, show a peak near $16 \mathrm{~K}$ (Fig. 6(a)). This behavior was found, with very little variance, for all studied samples. It can be interpreted as a shift of blocking temperatures towards higher values by a strong steady field (Néel, 1949, 1955). This is further illustrated by the susceptibility curves measured in intermediate steady fields (Fig. 6(b)). A $500 \mathrm{mT}$ field is too weak to shift the susceptibility peak to the range accessible with an MPMS instrument, although the change in the shape of the curve suggests that a peak occurs at a higher temperature than in the zero field. A $2.5 \mathrm{~T}$ field shifts the peak in the susceptibility curve further, to 7-8 K. This particular shape of the susceptibility vs. temperature curves means that, at low temperature, samples cannot be saturated even in the highest
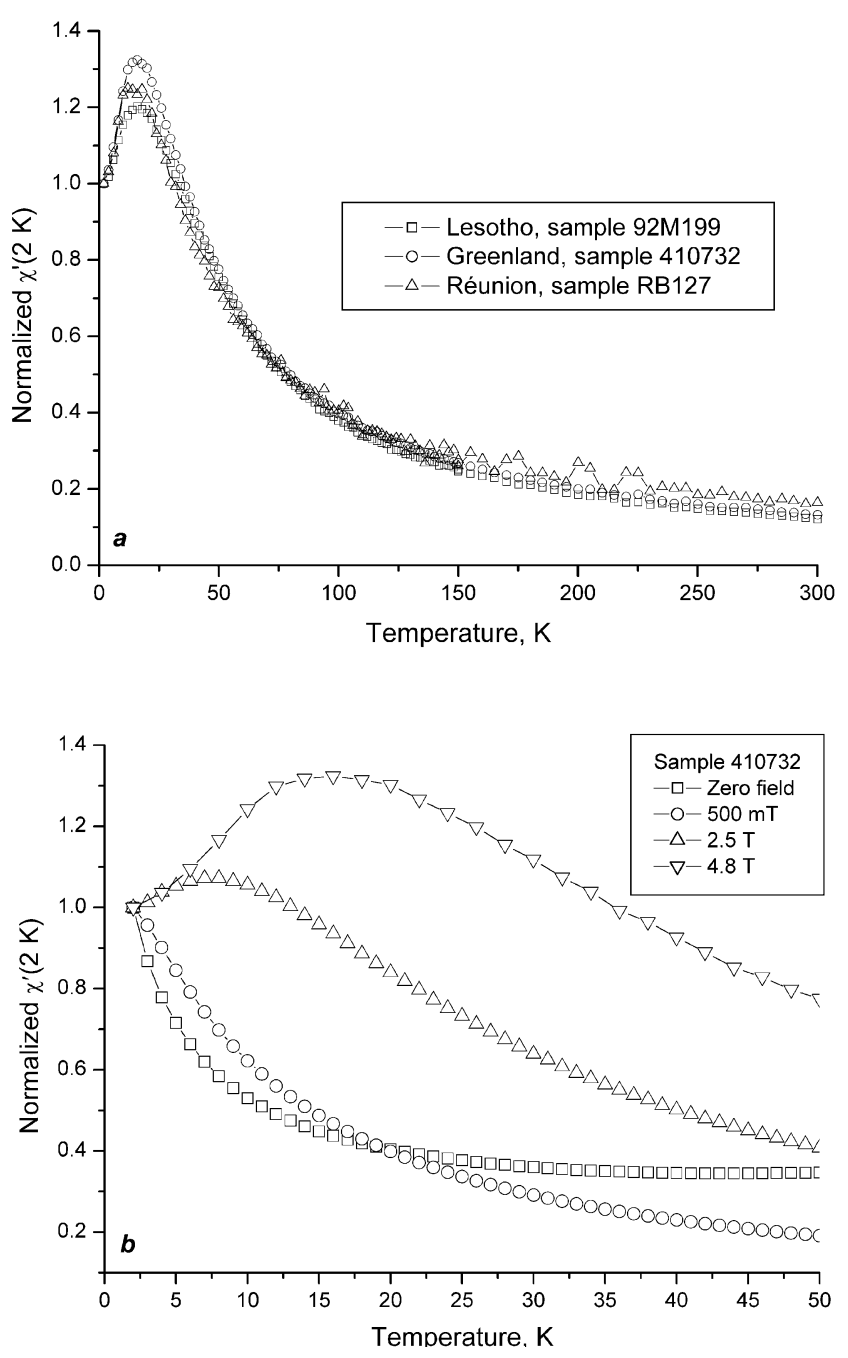

Fig. 6. Examples of strong-field susceptibility vs. temperature curves (a), and a comparison of normalized susceptibility vs. temperature curves measured in various DC biasing fields (b).

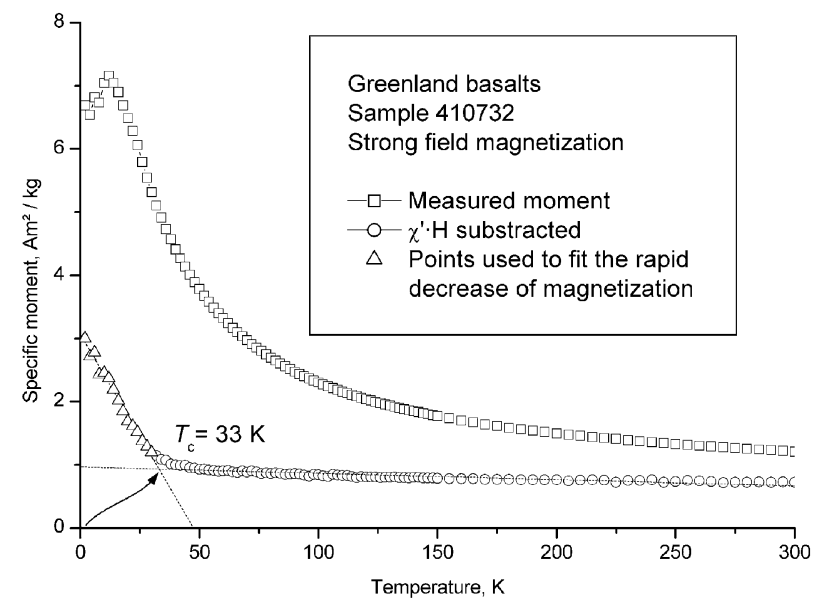

Fig. 7. To the determination of the Curie temperature of the low-temperature phase. The Curie point was defined as an intersection of the linear fit of the strong decrease of magnetization at low temperatures (shown by triangles) with the baseline representing a signal from the titanomagnetite phase. 

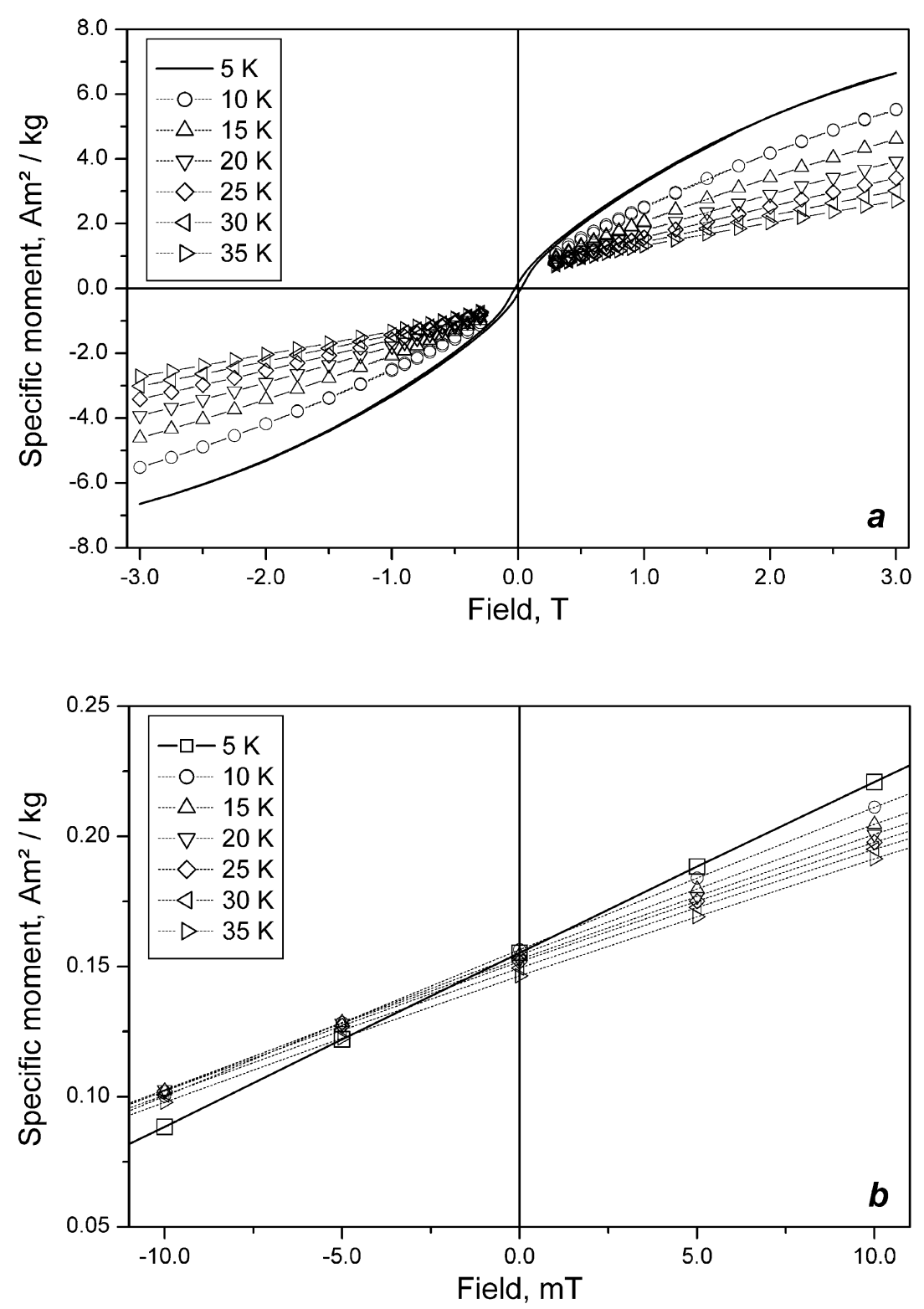

Fig. 8. Hysteresis loops for the sample 410732 measured from 5 to $35 \mathrm{~K}$. (b) shows part of the descending branch of the loops in small fields. The low-temperature phase acquires only a very small remanence.

fields produced by the MPMS instrument.

It seems impossible that magnetite (or titanomagnetite) alone can account for this behavior, since this would require an unrealistically large amount of extremely fine, less than $5 \mathrm{~nm}$ in size, grains. While the presence of superparamagnetic (titano)magnetite grains has been documented in some volcanic rocks, most notably in the Yucca Mountain Tuff (Worm and Jackson, 1999), it is not so common in lavas. A working hypothesis would be then that another magnetic phase is present, designated below for brevity as the lowtemperature phase. The determination of the Curie temperature of this phase is not so straightforward as for the titanomagnetite phase. The temperature, at which a peak occurs in the high-field (4.8 T) susceptibility curves, is obviously its lower limit. However, since the low-temperature phase is still not saturated in this field, its true Curie point has to be somewhat higher. A more precise method is to subtract the induced moment $\left(\chi^{\prime} \cdot H\right.$, where $H=4.8 \mathrm{~T}$ is the applied steady field) from the total measured moment, and to determine the Curie point from the resulting temperature dependence of a strong-field magnetization, as illustrated in Fig. 7. However, a sample is not truly saturated below the transition temperature, and its measured susceptibility includes a contribution from the low-temperature phase itself. A strongfield magnetization obtained as described above therefore underestimates the true $M_{s}$ value. Even though, this method apparently gives a reasonable estimate for the transition temperature, which typically ranges from 21 to $29 \mathrm{~K}$. Two notable exceptions are sample 410732 from Greenland (Fig. 7) and sample 92M199 from Lesotho, whose transition temperatures are 33 and $40 \mathrm{~K}$, respectively. It is also worth noting that at $2 \mathrm{~K}$ the low-temperature phase may account for up to 75 per cent of the total magnetization.

Hysteresis properties of the low-temperature phase are 

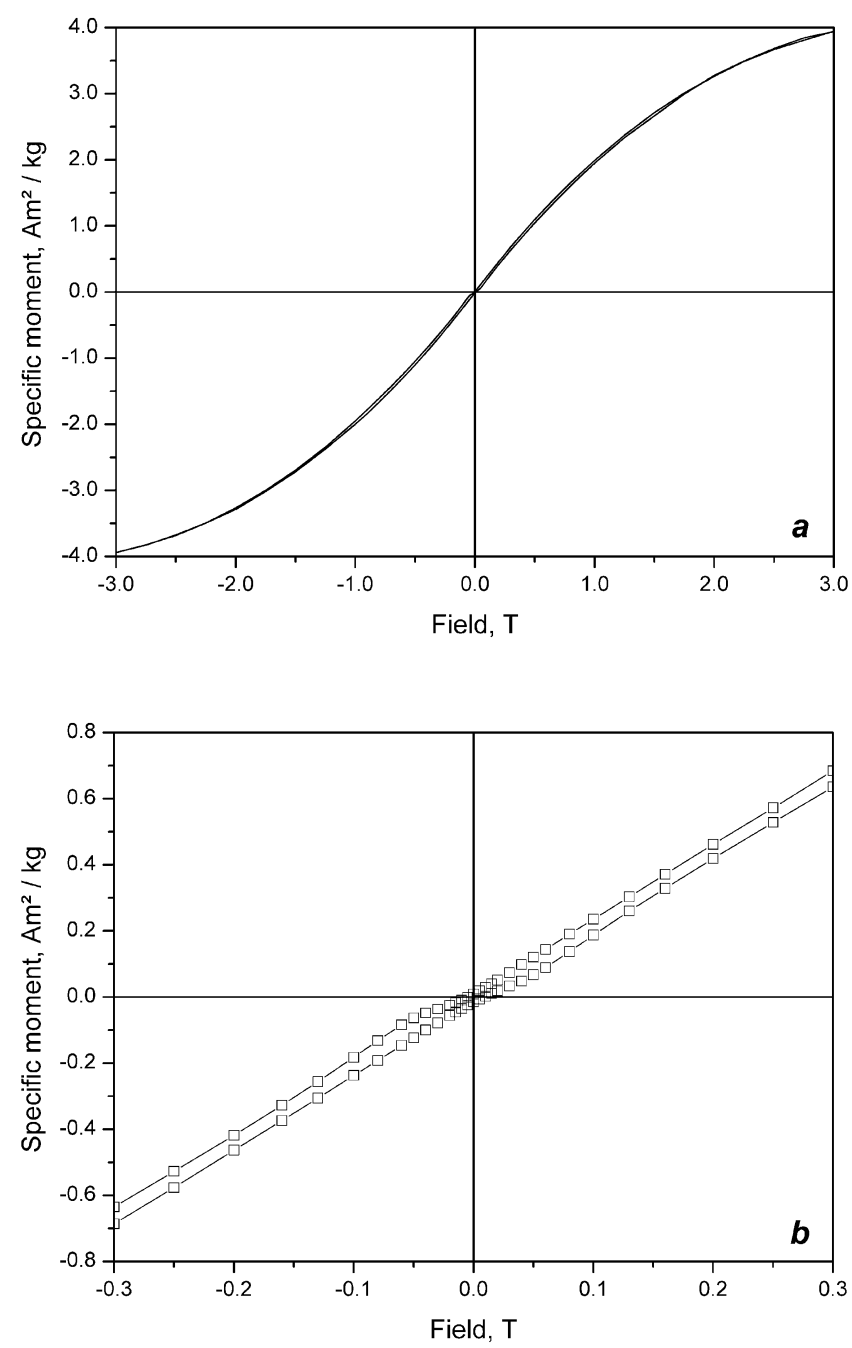

Fig. 9. 'Difference' hysteresis loop for the sample 410732 obtained by subtraction of the loop measured at $35 \mathrm{~K}$ from that measured at $5 \mathrm{~K}$. Note an almost superparamagnetic character of the loop.

also very peculiar. Since hysteresis measurements with an MPMS instrument are extremely time-consuming (several hours for one loop), hysteresis (in a $3 \mathrm{~T}$ maximum field) at different temperatures from 5 to $90 \mathrm{~K}$ was only measured for a few selected samples. An example of hysteresis loops is given in Fig. 8. Below the Curie point of the lowtemperature phase $(33 \mathrm{~K})$, the magnetization shows only a weak tendency to saturation. At the same time, in small fields this phase apparently does not acquire any significant remanence, as illustrated in Fig. 8(b). However, in measured hysteresis loops, properties of the low-temperature phase are masked by the contribution from the titanomagnetite phase. I therefore attempted to 'extract' the loop characterizing the low-temperature phase alone by subtracting the loop measured at $35 \mathrm{~K}$ from the loop measured at $5 \mathrm{~K}$. Assuming that the hysteresis properties of the titanomagnetite phase do not change much in this temperature interval, we can consider the resulting difference loop (Fig. 9) as an approximate estimate of hysteresis in the low-temperature phase. Already at $5 \mathrm{~K}$ it reveals largely superparamagnetic behavior, with perhaps very small hysteresis.

The properties of remanent magnetization of the low-tem-

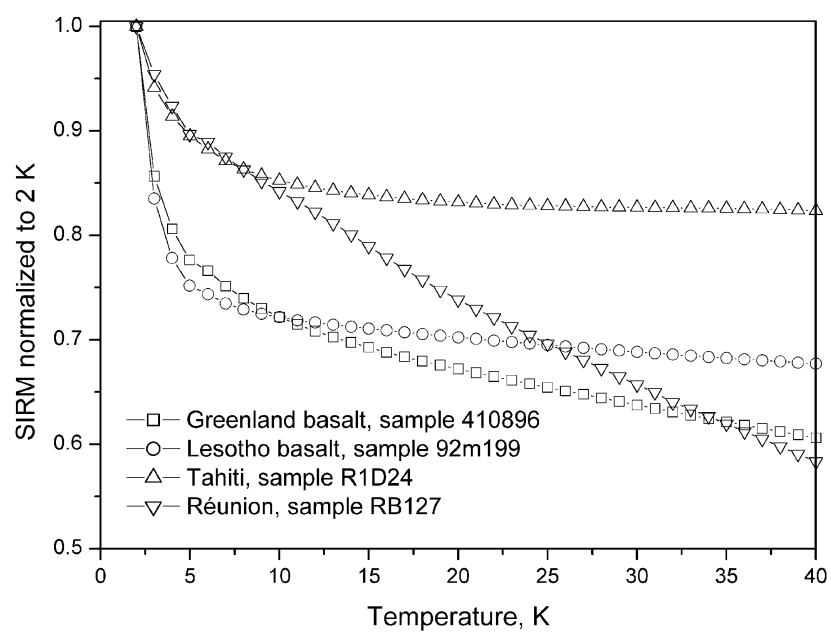

Fig. 10. Thermal demagnetization of SIRM given at $2 \mathrm{~K}$. Low-temperature phase apparently acquires some remanence at this temperature, but it largely disappears by $5 \mathrm{~K}$.

perature phase was investigated further by means of the decay on zero-field warming of SIRM (5 T) given at $2 \mathrm{~K}$. Typical SIRM(T) curves are shown in Fig. 10. Considerable remanence can be apparently acquired by the low-temperature phase at $2 \mathrm{~K}$, but it is extremely unstable and has largely disappeared at $5 \mathrm{~K}$, the lowest temperature at which hysteresis measurements have been performed. The behavior of plateau basalts and 'hotspot' rocks seems to be somewhat different, the low-temperature phase of the latter acquiring a relatively less-intense remanence at $2 \mathrm{~K}$.

\section{Discussion}

Taken together, the observed magnetic properties at very low temperatures allow to constrain a range of possible mineral phases that may be responsible for this behavior. The non-zero remanence, presence of hysteresis, and the dependence of the peak in the susceptibility curves on the applied steady bias field all suggest that below the transition temperature the hypothetical low-temperature phase is a ferromagnet rather than an antiferromagnet. This effectively rules out iron-bearing silicates as an explanation for the above properties. Indeed, although below about $70 \mathrm{~K}$ iron-rich olivines and pyroxenes show peaks in susceptibility vs. temperature curves (Santoro et al., 1966; Sawaoka et al., 1968) which are the signature of an antiferromagnetic ordering, the dilution of iron by magnetically inactive cations such as $\mathrm{Mg}^{2+}$ strongly decreases the respective Néel temperatures and eventually suppresses the antiferromagnetic transition (Hoye and O'Reilly, 1972).

Moskowitz et al. (1998) have reported a peak at about $50 \mathrm{~K}$ in the susceptibility vs. temperature curve of a sample of basalt from an Hawaiian deep drill hole. This peak was attributed to ilmenite which had been observed as a separate oxide phase in a thin section from nearby samples. The magnetic properties of ilmenite have also been extensively studied within the context of lunar mineralogy (Senftle et al., 1975; Thorpe et al., 1977) and kimberlite/diamond exploration (Brodskaya and Zaytseva, 1976; Lethuillier and Massal, 1980; Yakubovskaya and Ilupin, 1982; 
Yakubovskaya and Fradkov, 1986; Potapov et al., 1994). Néel temperatures have been reported in the 40-60 K range, the lower values being characteristic of the terrestrial samples where a small amount of hematite is always present (Thorpe et al., 1977; Yakubovskaya and Fradkov, 1986). Below Néel temperature ilmenite and hemoilmenites with up to 6.6 mole per cent of hematite (Thorpe et al., 1977) become antiferromagnetic and carry no remanence. This is clearly different from the behavior found in the present study. Also, in our basalts a separate ilmenite phase was not seen in the microscopic observations. It may be therefore concluded that ilmenite does not make a significant contribution to the observed low-temperature magnetic properties.

Another candidate to account for the above properties is a hemoilmenite phase, produced in the high-temperature deuteric oxidation (Buddington and Lindsley, 1964; Haggerty, 1976). Exsolved titanomagnetite grains with hemoilmenite lamellae are abundant in most of our samples. The magnetic properties of hemoilmenites have been investigated previously using the synthetic samples (Bozorth et al., 1957; Ishikawa and Akimoto, 1957; Ishikawa, 1962). Samples in the composition range $x \leq 0.21$ in the formula $x \mathrm{Fe}_{2} \mathrm{O}_{3} \cdot(1-$ $x) \mathrm{FeTiO}_{3}$ show peaks in the high-field $(2 \mathrm{~T})$ magnetization curves which shift towards lower temperatures with increasing hematite content. At the same time, the magnetization in a $2 \mathrm{~T}$ field, measured at $2 \mathrm{~K}$, increases and reaches about $100 \mathrm{Am}^{2} / \mathrm{kg}$ for the sample with 21 per cent of hematite (Ishikawa, 1962). However, for more hematite-rich compositions, with $x=0.17$ and 0.21 , hysteresis is still observed at least up to 80 and $250 \mathrm{~K}$ respectively. The $x=0.08$ and 0.12 compositions show hysteresis up to about $30 \mathrm{~K}$. Above this temperature, magnetization curves only show inflections around zero field, characteristic of superparamagnetism. Remanent magnetization of these samples is relatively small, particularly for the $x=0.08$ sample, and thermally unstable. Ishikawa (1962) suggested a model of the magnetic structure of ilmenite-rich hemoilmenites, where small ferromagnetically ordered clusters are embedded in an antiferromagnetic matrix. These clusters effectively behave as an assemblage of fine magnetic particles, becoming superparamagnetic above the blocking temperature.

However, a substantial discrepancy exists between the observations in the present work and the properties of hemoilmenites known from the previous studies. Curie points of the low-temperature phase in our basalts are typically in the 20-30 K range. Accordingly, superparamagnetic behavior is only observed below this temperature, and the magnetic hysteresis above about $30 \mathrm{~K}$ is entirely due to the titanomagnetite phase. Peaks in the high-field magnetization of our samples, if any, occur at 5-6 K at most. In part, this difference may be due to the fact that the previous studies have used synthetic samples. While representing the single phases of a particular composition, these samples had been quenched from a high temperature during synthesis. In nature, deuteric oxidation proceeds over much longer timescales, which may result in a more homogeneous crystalline structure. Apparently, hemoilmenites in our basalts have the hematite content which is sufficient to superpose a ferrimagnetic order over the basic antiferromagnetic order of ilmenite. A more homogeneous distribution of $\mathrm{Fe}^{3+}$ cations than in the synthetic samples naturally results in a weaker exchange and, hence, in lower Curie temperatures.

The co-existence of a hemoilmenite phase with low-Ti titanomagnetites (carrying NRM) indicates a close genetic relationship between the two phases. This is supported by the results of the oxidation experiments of Tucker and O'Reilly (1980). In this study, a single crystal of nominal TM60 composition was subjected to oxidation at $1275^{\circ} \mathrm{C}$ and at progressively increasing, up to $10^{-3}$, partial oxygen pressures. The most extreme degrees of oxidation (parameter $z>0.8)$ resulted in a small $(1-7 \%$ by volume) amount of near-magnetite phase forming within the matrix of coexisting hemoilmenite and pseudobrookite. This somewhat resembles our samples where titanomagnetite contributes only about 30 per cent of the total magnetization at $2 \mathrm{~K}$, indicating that, at most, it accounts for about 10 per cent of the magnetic material.

\section{Conclusion}

For a collection of basalts of different origin and age, magnetic measurements at low temperatures have revealed that, besides a phase carrying remanent magnetization at room temperature, another magnetic phase with Curie temperatures in the $20-30 \mathrm{~K}$ range, is present in all samples without exception. Below its Curie temperature this phase is extremely magnetically hard, not reaching saturation even in the $5 \mathrm{~T}$ field. On the other hand, it acquires a relatively strong remanence only at very low temperatures, on the order of $2 \mathrm{~K}$. SIRM carried by this phase is largely demagnetized at $10 \mathrm{~K}$, indicating superparamagnetic behavior. Further evidence for superparamagnetism is the observed gradual shift of blocking temperatures towards higher values by a strong steady field.

A possible candidate for this low- $\mathrm{T}_{c}$ phase is ferrimagnetic hemoilmenite with $8-10$ mole $\%$ of hematite, although some discrepancies exist between the observed behavior of the basalts studied and the data previously reported for this material. High-field magnetization of hemoilmenites of this composition is several times smaller than that of magnetite but, on the other hand, at very low temperatures it contributes up to 70 per cent of the total high-field magnetization of the studied samples. Hemoilmenite has therefore to be vastly greater in abundance by volume than the Ti-poor titanomagnetite phase.

Acknowledgments. My interest in the magnetic properties of basalts was initiated during my Ph.D study at Laboratoire de Géophysique et Tectonique, Université Montpellier II, when this project was started. I am immensely grateful to Michel Prévot for his guidance at this stage, and also for pointing out to me Ishikawa's (1962) paper. The low temperature measurements that form the core of this study were carried out at the Geological Survey of Japan, where the author's stay was made possible through a Science and Technology Agency (Japan) postdoctoral fellowship. I am grateful to Toshitsugu Yamazaki, my host at the GSJ, and to Hirokuni Oda for the many scientific and technical discussions we had during my stay. Annick Chauvin and Peter Riisager kindly supplied rock samples for the present study. I thank Isoji Miyagi for his invaluable help with SEM observations. Some measurements at low temperatures were carried out at the Institute of Rock Magnetism, University of Minnesota, thanks to an IRM Visiting Fellowship in March 1997. This paper has greatly benefited from the reviews of Masayuki Torii and an anonymous reviewer. I thank 
the EPS editor, Dr Hidefumi Tanaka, for the effective handling of the manuscript.

\section{References}

Aragón, R., Magnetization and exchange in nonstoichiometric magnetite, Phys. Rev. B, 46, 5328-5333, 1992.

Aragón, R., D. J. Buttrey, J. P. Shepherd, and J. M. Honig, Influence of nonstoichiometry on the Verwey transition, Phys. Rev. B, 31, 430-436, 1985.

Banerjee, S. K., Magnetic properties of Fe-Ti oxides, in Oxide Minerals: Petrologic and Magnetic Significance, edited by D. L. Lindsley, pp. 107128, Mineralogical Society of America, 1991.

Bozorth, R. M., D. E. Walsh, and A. J. Williams, Magnetization of ilmenitehematite system at low temperatures, Phys. Rev., 108, 157-158, 1957.

Brabers, V. A. M., F. Walz, and H. Kronmüller, Impurity effects upon the Verwey transition in magnetite, Phys. Rev. B, 58, 14163-14166, 1998.

Brodskaya, S. Yu. and G. M. Zaytseva, Magnetic characteristics of hemoilmenites with low Curie points, Izv., Earth. Phys., 12, 219-223, 1976.

Buddington, A. F. and D. H. Lindsley, Iron-titanium oxide minerals and synthetic equivalents, J. Petrol., 5, 310-357, 1964.

Chauvin, A., P. Roperch, and R. A. Duncan, Records of geomagnetic reversals from volcanic islands of French Polynesia 2. Paleomagnetic study of a flow sequence (1.2-0.6 Ma) from the Island of Tahiti and discussion of reversal models, J. Geophys. Res., 95, 2727-2752, 1990.

Chauvin, A., P.-Y. Gillot, and N. Bonhommet, Paleointensity of the Earth's magnetic field recorded by two Late Quaternary volcanic sequences at the Island of La Réunion (Indian Ocean), J. Geophys. Res., 96, 19812006, 1991.

Clark, D. A. and P. W. Schmidt, Theoretical analysis of thermomagnetic properties, low-temperature hysteresis and domain structure of titanomagnetites, Phys. Earth Planet. Inter, 30, 300-316, 1982.

Dunlop, D. J. and Ö. Özdemir, Rock Magnetism: Fundamentals and Frontiers, 573 pp., Cambridge University Press, Cambridge, New York, 1997.

Haggerty, S. E., Oxidation of opaque mineral oxides in basalts, in Oxide Minerals, edited by D. Rumble, pp. $\mathrm{Hg} 1-\mathrm{Hg} 100$, Mineralogical Society of America, 1976.

Hodych, J. P., Magnetic hysteresis as a function of low temperature for deep-sea basalts containing large titanomagnetite-inference of domain state and controls on coercivity, Can. J. Earth Sci., 19, 144-152, 1982.

Hodych, J. P., Magnetic hysteresis as a function of low temperature in rocks: evidence for internal stress control of remanence in multi-domain and pseudo-single-domain magnetite, Phys. Earth Planet. Inter., 64, $21-$ 36, 1990.

Hodych, J. P., Low-temperature demagnetization of saturation remanence in rocks bearing multidomain magnetite, Phys. Earth Planet. Inter., 66, 144-152, 1991.

Hoye, G. S. and W. O'Reilly, A magnetic study of the ferro-magnesian olivines $\left(\mathrm{Fe}_{x} \mathrm{Mg}_{1-x}\right)_{2} \mathrm{SiO}_{4}, 0<x<1$, J. Phys. Chem. Solids, 33, $1827-$ 1834, 1972.

Ishikawa, Y., Magnetic properties of ilmenite-hematite system at low temperature, J. Phys. Soc. Jpn., 17, 1835-1844, 1962.

Ishikawa, Y. and S. Akimoto, Magnetic properties of the $\mathrm{FeTiO}_{3}-\mathrm{Fe}_{2} \mathrm{O}_{3}$ solid solution series, J. Phys. Soc. Jpn., 12, 1083-1098, 1957.

Kosterov, A. A. and M. Prévot, Possible mechanisms causing failure of Thellier palaeointensity experiments in some basalts, Geophys. J. Int., 134, 554-572, 1998.

Kosterov, A. A., M. Prévot, M. Perrin, and V. A. Shashkanov, Paleointensity of the Earth's magnetic field in Jurassic: new results from a Thellier study of the Lesotho Basalt, Southern Africa, J. Geophys. Res., 102, 24859-24872, 1997.

Kosterov, A. A., M. Perrin, J. M. Glen, and R. S. Coe, Paleointensity of the Earth's magnetic field in Early Cretaceous time: The Parana Basalt, Brazil, J. Geophys. Res., 103, 9739-9753, 1998.

Kozłowski, A., P. Metcalf, Z. Kakol, and J. M. Honig, Electrical and magnetic properties of $\mathrm{Fe}_{3-z} \mathrm{Al}_{z} \mathrm{O}_{4}(z<0.06)$, Phys. Rev. B, 53, 1511315118, 1996a.

Kozłowski, A., Z. Kakol, D. Kim, R. Zaleski, and J. M. Honig, Heat capacity of $\mathrm{Fe}_{3-\alpha} \mathrm{M}_{\alpha} \mathrm{O}_{4}(\mathrm{M}=\mathrm{Zn}, \mathrm{Ti}, 0 \leq \alpha \leq 0.04)$, Phys. Rev. B, 54, 12093-12098, 1996b.

Lethuillier, P. and P. Massal, Propriétés magnétiques de grenats et d'ilménites naturels prélevés dans des gisements variés, Bull. Minéral. 103, 33-39, 1980

Merrill, R. T., Low-temperature treatments of magnetite and magnetitebearing rocks, J. Geophys. Res., 75, 3343-3349, 1970.
Moskowitz, B. M., M. Jackson, and C. Kissel, Low-temperature magnetic behavior of titanomagnetites, Earth Planet. Sci. Lett., 157, 141-149, 1998.

Nagata, T., K. Kobayashi, and M. D. Fuller, Identification of magnetite and hematite in rocks by magnetic observations at low temperature, $J$. Geophys. Res., 69, 2111-2120, 1964.

Néel, L., Théorie du trainage magnétique des ferromagnétiques en grains fins avec applications aux terres cuites, Ann. Geophys., 5, 99-136, 1949.

Néel, L., Some theoretical aspects of rock-magnetism, Adv. Phys., 4, 191243, 1955.

O'Reilly, W., Rock and Mineral Magnetism, 220 pp., Blackie, Glasgow and London, \& Chapman and Hall, New York, 1984.

Potapov, G. A., L. N. Romashov, B. B. Zhalsabon, and V. M. Lapushkov, Some peculiarities of magnetic structure and properties of ilmenite varieties, Izv., Earth Phys., 30, 365-368, 1994.

Radhakrishnamurty, C., S. D. Likhite, E. R. Deutsch, and G. S. Murthy, A comparison of the magnetic properties of synthetic titanomagnetites and basalts, Phys. Earth Planet. Inter., 26, 37-46, 1981.

Riisager, P. and N. Abrahamsen, Palaeointensity of West Greenland Palaeocene basalts: asymmetric intensity around the $\mathrm{C} 27 \mathrm{n}-\mathrm{C} 26 \mathrm{r}$ transition, Phys. Earth Planet. Inter., 118, 53-64, 2000.

Santoro, R. P., R. E. Newham, and S. Nomura, Magnetic properties of $\mathrm{Mn}_{2} \mathrm{SiO}_{4}$ and $\mathrm{Fe}_{2} \mathrm{SiO}_{4}$, J. Phys. Chem. Solids, 27, 655-666, 1966.

Sawaoka, A., S. Miyahara, and S. Akimoto, Magnetic properties of several metasilicates and metagermanates with pyroxene structure, J. Phys. Soc. Jpn., 25, 1253-1257, 1968.

Senanayake, W. E. and M. W. McElhinny, Hysteresis and susceptibility characteristics of magnetite and titanomagnetites: interpretation of results from basaltic rocks, Phys. Earth Planet. Inter, 26, 47-55, 1981.

Senanayake, W. E. and M. W. McElhinny, The effects of heating on lowtemperature hysteresis and susceptibility properties of basalts, Phys Earth Planet. Inter, 30, 317-321, 1982.

Senftle, F. E., A. N. Thorpe, C. Briggs, C. Alexander, J. Minkin, and D. L. Griscom, The Néel transition and magnetic properties of terrestrial, synthetic, and lunar ilmenites, Earth Planet. Sci. Lett., 26, 377-386, 1975.

Shau, Y.-H., M. Torii, C.-S. Horng, and D. R. Peacor, Subsolidus evolution and alteration of titanomagnetite in ocean ridge basalts from Deep Sea Drilling Project/Ocean Drilling Program Hole 504B, Leg 83: Implications for the timing of magnetization, J. Geophys. Res., 105, 2363523649, 2000.

Sherwood, G. J., Rock magnetic studies of Miocene volcanics in eastern Otago and Banks Peninsula, New Zealand; comparison between Curie temperature and low temperature susceptibility behaviour, New Zealand J. Geol. Geophys., 31, 225-235, 1988.

Šimša, Z., F. Zounová, and S. Krupička, Initial permeability of single crystal magnetite and Mn-ferrite, Czech. J. Phys. B, 35, 1271-1281, 1985.

Skumryev, V., H. J. Blythe, J. Cullen, and J. M. D. Coey, AC susceptibility of a magnetite crystal, J. Magn. Magn. Mater., 196-197, 515-517, 1999.

Syono, Y., Magnetocrystalline anisotropy and magnetostriction of $\mathrm{Fe}_{3} \mathrm{O}_{4}$ $\mathrm{Fe}_{2} \mathrm{TiO}_{4}$ series - with special application to rocks magnetism, Jpn. J. Geophys., 4, 71-143, 1965.

Thellier, E. and O. Thellier, Sur l'intensité du champ magnétique terrestre dans le passé historique et géologique, Ann. Geophys., 15, 285-376, 1959.

Thomas, N., An integrated rock magnetic approach to the selection or rejection of ancient basalt samples for palaeointensity experiments, Phys Earth Planet. Inter., 75, 329-342, 1993.

Thorpe, A. N., J. A. Minkin, F. E. Senftle, C. Alexander, C. Briggs, H. T. Evans, Jr., and G. L. Nord, Jr., Cell dimensions and antiferromagnetism of lunar and terrestrial ilmenite single crystals, J. Phys. Chem. Solids, 38, 115-123, 1977.

Tucker, P. and W. O'Reilly, The laboratory simulation of deuteric oxidation of titanomagnetites: effect on magnetic properties and stability of thermoremanence, Phys. Earth Planet. Inter. 23, 112-133, 1980

Worm, H. U. and M. Jackson, The superparamagnetism of Yucca Mountain Tuff, J. Geophys. Res., 104, 25415-25425, 1999.

Yakubovskaya, N. Yu. and I. P. Ilupin, Magnetic properties of picroilmenite from kimberlites of Siberia, Mineral. J., 4(5), 36-43, 1982 (in Russian with English abstract).

Yakubovskaya, N. Yu. and V. A. Fradkov, Magnetic structure of ilmenite, Mem. All-Union Min. Soc., 115, 490-495, 1986 (in Russian).

A. Kosterov (e-mail: kosterov@geo.titech.ac.jp) 